\title{
Mentiras a casi 200 años
}

\section{Lies to almost 200 years}

\author{
Yesika Felix Montoya ${ }^{a}$
}

\begin{abstract}
:
Photography essentially speaks of the past and the photographer's lies; representations that have illustrated the world before the action of contemplation and the magic of abstracting part of it in each image made. The approach of the camera captures reality is wrong, because this, reality, is as false as the fact that what is photographed in three dimensions is recreated in a two-dimensional space. The adaptation that responds intrinsically to the themes and technical possibilities, shows us an evolution close to the extinction of the tangible object of a printed image. However, this mutation has allowed the democratization of the image culture, its diverse uses, and its degrees of symbolism and iconicity.
\end{abstract}

The image as a synonym of truth has always depended on the subjectivity of the photographer, ambiguity that enters a dichotomy between the false - true, art - record, original - copy, this reality invented or created from the gaze in search of the conception of what the photographer considers beautiful.

Walter Benjamín, in Little History of Photography 1931, suggests to us as an axis of thought that photography is not necessarily a reproduction of the conception of reality, since it proposes the construction of a new reality; which without photography it would not be possible to observe and understand details that would go unnoticed and misunderstood even with the most attentive gaze. This idea is taken up again, in 1936, in "The work of art at the time of its technical reproducibility" when he says that "in photography aspects of the original accessible only to a lens managed at will can be highlighted in order to select various points of view, instead inaccessible to the human eye. "

Walter Benjamin's reflections are later taken up and in some way digested and sintered in the work of Susan Sontag in his essay To understand photography, where he takes up again this contemplation of the beauty and the gaze of each of the photographers, who at his Consideration they create images of what they consider beautiful in this search for beauty: the construction of the image and its abstraction.

From the Daguerreotype, to Instagram, the lies that currently flood social networks and are shared every second throughout the world, an invention that continues to convince everyone of their lies and create the addictive power of the image, in a connected world. From black and white to color, from metal plate to paper and today assuming itself as one of the main characters in the digital space.

This writing gives a particular point of view of how through the years of the invention of photography, it has gone through various scenarios and controversies, calling into question whether it is art or not, whether it is a faithful record of reality or an interpretation characteristic of the photographer's language as an expressive tool. It is divided into four different scenarios where this dichotomy of reality - not real, lies - truth is posed, reaching a conclusion of this evolution.

\section{Keywords:}

Photography, Lies, Photographer, Representations, Reality, Evolution, Social Networks

\section{Resumen:}

La fotografía en esencia, habla del pasado y de las mentiras del fotógrafo; representaciones que han ilustrado el mundo ante la acción de la contemplación y la magia de abstraer parte de él en cada imagen realizada. El planteamiento de que la cámara captura la realidad es erróneo, pues ésta, la realidad, es tan falsa como el hecho de que lo fotografiado en tres dimensiones se recree en un espacio bidimensional. La adaptación que responde intrínsecamente a las temáticas y posibilidades de técnicas, nos muestra una evolución cercana a la extinción del objeto tangible de una imagen impresa. Sin embargo, esta mutación ha permitido la democratización en la cultura de la imagen, sus usos diversos y sus grados de simbolismo e iconicidad.

La imagen como sinónimo de la verdad siempre ha dependido de la subjetividad del fotógrafo, ambigüedad que entra en una dicotomía entre lo falso-verdadero, arte-registro, original-copia, esta realidad inventada o creada de la mirada en búsqueda de la concepción de lo que el fotógrafo considere bello.

\footnotetext{
Universidad de Guadalajara, Centro Univeristario de la Costa, https://orcid.org/0000-0002-0059-6663, Email: yesika.felix@academicos.udg.mx
} 
Walter Benjamín, en Pequeña historia de la fotografía 1931, nos plantea como eje de pensamiento que la fotografía no necesariamente es una reproducción de la concepción que se tiene de la realidad, ya que propone la construcción de una nueva realidad; la cual sin la fotografía no sería posible observar y comprender detalles que pasarían desapercibidos eh incomprendidos aún con la mirada mas atenta. Esta idea la retoma, en 1936, en "La obra de arte en la época de su reproductibilidad técnica" cuando dice que "en la fotografía se pueden resaltar aspectos del original accesibles únicamente a una lente manejada a propio antojo con el fin de seleccionar diversos puntos de vista, inaccesibles en cambio para el ojo humano".

Las reflexiones de Walter Benjamin mas tarde son retomados y de alguna forma digeridos y sinterizados en la obra de Susan Sontag en su ensayo Para entender la fotografía, donde retoma esta contemplación de la belleza y la mirada de cada uno de los fotógrafos, que a su consideración crean imágenes de lo que consideran bello en esta búsqueda de la belleza: la construcción de la imagen y la abstracción de la misma.

Desde el Daguerrotipo, hasta el Instagram las mentiras que en la actualidad inundan las redes sociales y se comparten en cada segundo a lo largo y ancho del mundo, un invento que sigue convenciendo a todos de sus mentiras y creando el poder adictivo de la imagen, en un mundo conectado. Del blanco y negro al color, de la placa de metal al papel y hoy en día asumiéndose como uno de los personajes principales en el espacio digital.

Este escrito da un particular punto de vista de cómo a través de los años de la invención de la fotografía, ha pasado por varios escenarios y polémicas, poniendo en entredicho si es arte o no, si es un registro fiel de la realidad o una interpretación propia del lenguaje del fotógrafo como herramienta expresiva. Está dividido en cuatro escenarios diferentes donde se plantea esta dicotomía de la realidad - no real, la mentira - la verdad, llegando a una conclusión de esta evolución.

\section{Palabras Clave:}

Fotografía, Mentiras, Fotografo, Representación, Realidad, Evolución, Redes Sociales

\section{Introducción}

Hace mas de dos décadas que me enfrento ante el ojo de cristal, por el puedo vislumbrar mi historia particular de vida, y cómo el uso de la imagen fotográfica ha sido testigo de mi formación del lenguaje visual en mi proceso de creación artística, así como motivo de reflexión estudio y enseñanza del mismo. Puedo decir que en los tiempos de estudiante de Artes hasta profesor de fotografía no he terminado de maravillarme con la posibilidad estética y fuerza expresiva de la creación de la imagen fotográfica. La imagen como generador de una mega memoria colectiva que hace que conozcamos el mundo, este vasto y diverso mundo que por medio de los particulares puntos de vista, de la concepción de la belleza y la decisión de abstracción de el. Así hemos podido conocer; viajar en el tiempo, recorrer calles en diversos continentes, visitar vestigios arqueológicos, ver y conocer la muerte, enfrentarnos y confrontarnos con la guerra, con la siguiente guerra y con pandemias. En estos tiempos de coronavirus la imagen esta siendo no solo un testigo mudo, al dar testimonio, tanto científico como a nivel humano, si no como un soldado mas en la lucha contra la distancia, el dolor, la soledad, el vacío y la ausencia, haciéndose presente en cada espacio, y rincón, metiéndose en la intimidad de cada hogar y presentándonos una construcción de la realidad global. Del blanco y negro al color, de la placa de metal al papel y hoy en día asumiéndose como uno de los personajes principales en el espacio digital. En principio podemos vislumbrar el mundo por medio de esta concepción de la realidad. Este mundo representado que nos muestra la mirada curiosa del fotógrafo aficionado; donde captura su cotidiano, lo que le hace feliz, le asombra y le conmueve, mostrando su propio contexto. Al paso del tiempo, retratos familiares que se hicieron solo con la intención de preservar la memoria, se han convertido en piezas que son celosamente conservadas en museos por su gran valor antropológico y técnico, donde el fotógrafo quizá sea producto del anonimato. De igual manera el poder del lenguaje visual aplicado en la técnica fotográfica nos muestra una utilización mas planificada y con un fin establecido, imágenes poéticas y retoricas que asumió un papel predominante en el producto publicitario y de algunos fotógrafos de autor, imágenes que nos muestran un espacio onírico, al igual sin dejar de mencionar la herramienta poderosa que encontró y utiliza el artista visual en el desarrollo y planteamiento de su su discurso y por ende el proceso creativo que lo lleva a su producto final.

En suma, podemos descubrir y reconocer a través del análisis de la imagen una época, modo y gusto de una generación. Las imágenes son maestras de un mundo imaginario, paralelo y surrealista, que es capaz de conmovernos, sensibilizarnos, alentarnos; al igual que transgrede, denuncia propone nuevas lecturas de la imagen y su simbolismo, nos enfrenta a situaciones que si no hubieran sido documentadas, no creeríamos existentes. 


\section{Mentiras}

Hablar de fotografía es hablar casi de 200 años de historia. Podríamos enfocarnos a historia del arte, su incursión y la conmoción que desde su aparición creo, discutiendo si era arte o solo un aparato producto de la ciencia que permitía a cualquiera que la tuviera en sus manos el capturar la realidad sin ninguna alteración, demeritando la capacidad y cualidades estéticas y creativas que se producirían. O la historia de la humanidad, como uno de los inventos que revolucionó el siglo haciendo posible la democratización de la imagen, liberando a pintores, ilusionando a escritores y marchando junto a un mundo a punto de ebullición, donde todo estaba sucediendo desde la posibilidad de capturar el tiempo por medio de la fotografía, hasta la magia del proceso de la vulcanización que permitió que la industria automotriz floreciera.

A casi 90 años de que se diera a conocer oficialmente el invento de Daguerre en agosto del 1839, el filósofo de origen alemán Walter Benjamin, daba una reflexión acertada y casi profética de la imagen. $Y$ le cito en pequeña historia de la fotografía "No él que ignore la escritura, sino él que ignore la fotografía», se ha dicho, «será el analfabeto del futuro».

A lo largo de su historia, el perfeccionamiento de la técnica fotográfica desencadeno el imaginario visual tanto de científicos como de artistas, pintores que encontraban en el estudio de la luz una nueva temática que llevó a que plasmaran el mundo con una impresión diferente, a su vez, los diferentes y diversos usos desde científicos, antropológicos, y por qué no, militar y de espionaje en las grandes guerras. Mentiras de casi 200 años de fotógrafos que se convirtieron en leyendas, personajes que ahora se cuentan como mitos a las nuevas generaciones de futuros fotógrafos como referentes visuales, no solo de la imagen - la técnica, sino de la necesidad de documentar un mundo en constante evolución, una era de transición y de fusión, es hablar de las primeras técnicas fotográficas que ahora se ven como cosas rupestres, que se pueden recrear para dar un toque "vintage" a la imagen, o en un sentido del proceso creativo corresponde al discurso y el contexto, pero en realidad hablar de fotografía se trata de historias de vida, momentos totalmente íntimos que en complicidad con la cámara, fueron capaces de formar la magia de contar historias con la imagen. Sin embargo, hoy en día, hablar de fotografía es hablar de Instagram, Facebook, redes sociales, filtros, telefonía móvil, selfies.

Pareciera tan distante a las primeras imágenes solitarias que se conservan como "Vista desde la ventana en Le Gras" de Nicéhporo Niepce en 1826 donde se deslumbran algunas sombras entre la alumbra y penumbra de edificios que forman una composición geométrica, donde quizá la última finalidad fuera la estética.
A casi 200 años de la fotografía la acción de tomar fotos sigue en esencia intacta, sigue siendo ese momento íntimo de enfrentarse con el dispositivo que capturará lo que esperas de una realidad y la mentira que es la fotografía.

El mismo Walter Benjamin ya plantea la imagen fotográfica como un ente independiente y capaz de contar su propia versión de lo que se ve a través de lo fotografiado, pone como ejemplo a Eugene Atget, que en su registro de calle plasma la realidad que quiere ver, esta cotidianidad parisina de lo que el cree importante preservar y no la que necesariamente los demás autores de la época consideraban importante, se desprende de la pintura y retratos, para mostrarnos el principio del siglo XX con los cambios y profesiones cada vez mas en vías de extinción. Atget crea una gran colección de imágenes que si no hubiera sido por Berenice Abbott, quizá no en esta generación no seriamos testigos del Paris callejero de Atget. Walter Benjamin nos dice que su imagen es contemplada como fotografía de crimen, y nos acusa de ser criminales a cada uno de nosotros, por el hecho de transitar en este mundo y sus calles. Atget crea un documento que pareciera antropológico, donde la cotidianidad se convierte en surreal, escaparates, prostitutas, monumentos, reflejo de un ojo espontaneo y de una mirada que envuelve al espectador en un mundo subjetivo de personajes y rincones que no serian explorados de alguna otra forma, instantáneas que a pesar de la carencia técnica del momento de la toma, nos dan un aire de fragilidad y de nostalgia, de una ciudad casi etérea en un paisaje urbano, donde la ciudad es el pretexto de la imagen; sale de ese ruido, y bullicio y nos enseña lo sublime de la creación propia del hombre, sin que sea el mismo el personaje principal en la mayoría de las imágenes.

Las fotografías de la calle de Atget tratan de aferrarse a esta atmosfera parisina que fue construyendo lentamente el bullicio en silencio, la multitud en personajes en vías de extinción y la fuerza de la ciudad en una ciudad a mi parecer sublime de ensueño, la ciudad misma como personaje, los reflejos en los aparadores como muestra secundaria de los habitantes de la misma. Es así como el trabajo de Atget, lo consideran como surrealista, a pesar que nunca fue su intención.

Nacho López, al igual que Atget en Paris, fotografío el cambio de la Ciudad de México en los años cincuentas, su fotografía directa pero cubierta de mentiras, donde nada es lo que parece ser y a la vez lo es todo, su fotografía nos muestra una sociedad de contrastes, una ciudad viva, donde los protagonistas son nuevamente son pretextos para mostrar la verdad en blanco y negro de Nacho López, un pionero en el foto ensayo, pero sobre todo en la experimentación de la imagen, registrando fielmente la belleza a través de una burbuja de jabón el icónico edificio 
de Las Bellas Artes en el corazón del centro, como una modelo caminando lentamente ante las miradas asombradas de los protagonistas de la imagen, sus jacciones provocadasi son una forma de manipular la imagen, sus protagonistas son inducidos a reacciones involuntarias que Nacho López sabia retratar, junto a su venus que se fue de juerga, el maniquí femenino que acompaña a un hombre de sombrero a recorrer la ciudad, y la mirada incrédula de los que lo veían atento, es el mundo provocado de uno de los Fotógrafos mexicanos que se atrevieron a romper el molde, publicando en revistas estos foto ensayos, que quedan como registro de una ciudad en cambio, convenciendo a los demás de sus mentiras provocadas, donde los protagonistas, son activos actores involuntarios ante el ojo implacable de Nacho Lopéz.

Las mentiras subjetivas de plantear una realidad en la fotografía, es solo por la necesidad de expresión del fotógrafo, no importando la época o el lugar, la fotografía es el vehículo para conocer el mundo a través de las mentiras de los fotógrafos, su abstracción del mismo y la intencionalidad de interpretación con la convicción de resguardar una memoria sujeta a el olvido.

\section{Hasta no ver no creer}

Cuando a los fotógrafos de guerra les preguntan cómo soportan las condiciones que les toca documentar, e incluso el arriesgar sus propias vidas para hacerlo, la mayoría contestan "para hacer una diferencia".

En el documental "MacCullin"(2012), Donald MacCulling habla de su trabajo, su ética periodística, y su proceso natural y casi orgánico que lo llevo a registrar grandes conflictos armados a lo largo y ancho del mundo, el tratar de fotografiar la realidad sin manipulación de escenas, imágenes tan crudas que muestran parte ineludible de la condición humana. Documenta en cada imagen con todo el rigor estético la destrucción, muerte, hambrunas, muestra lo que pocos queremos cerca y pensamos que no nos afecta, personas matando personas, humanos que pierden su condición humana y espectadores que tienen que ver esas imágenes para comprender por lo que pasa la humanidad, sin embargo, de las primeras imágenes de MacCulling, mostrando su entorno salvaje, violento y complejo de las calles de Londres, a nuestra nuestros días donde uno podría cuestionarse esa ética periodística, ese deseo de sangre y de violencia del cual se saturan los medios, tanto por aficionados con un dispositivo móvil que suben a redes sociales en tiempo real escenas que escandalizarían a cualquier alma sensible y sin embargo la sociedad empieza a normalizar, hasta medios periodísticos en teoría "serios" que comparten las imágenes más sangrientas y sin ninguna curaduría con la única intencionalidad del vender.

Al final, al igual que Donald, el registrar hechos periodísticos es la culminación de ese ejercicio íntimo de contar historias, de acuerdo a la ética del fotógrafo, algunos lo más apegado a la realidad como sea posible, otros más, manipulando la imagen, pero al fin del día, sigue siendo esos segundos entre el fotógrafo, su cámara y el momento de hacer la toma y el resultado de la misma. Al igual que MacCulling Robert Capa años atrás busco el registro de su verdad, desde el lado del enemigo que le tocó fotografiar, podemos rápidamente ubicar su fotografía del día $D$, con toda esta fragilidad y crudeza al mismo tiempo de la imagen, donde la torpeza no intencionada del laboratorista crea una atmosfera que no fue la que vivió el mismo capa, pero que nos acerca mas a la fragilidad humana, en esas imágenes conmovedoras podemos ver y mas que ver, me atrevería a decir jsentir! la travesía del fotógrafo húngaro que se formo en los campos de batalla, siendo uno de los mejores fotógrafos de guerra.

En la actualidad es tan fácil mentir con las imágenes, se puede retomar una imagen de la red y publicarla en alguna red social, diciendo que es algo que pasa en este momento en alguna comunidad cercana o lejana, causando caos o admiración según el contenido, alejándose mas al contexto y quizá a la intencionalidad del fotógrafo, creando así lo que llamamos Faiking News, entre mas alejados a la intencionalidad del fotógrafo, mas descontextualizada será la imagen. Los registros de Guerra de Robert Capa, Donald MacCilling, de James Nachtway, son los registros particulares de su punto de vista, de su concepción subjetiva del bien y el mal, es en suma un lado de la moneda, vista y traducida en espectaculares imágenes icónicas que sin duda hicieron un cambio en la contemplación de la raza humana.

\section{Las ciudades fantasmas}

Al pensar en fotografía pensamos en el retrato, la necesidad humana de registrar nuestra imagen, nuestro transitar por el mundo, los cambios de edad, residencia, amigos, almanaques familiares que se hacían de forma analógica, guardando con cuidado, como verdaderas capsulas del tiempo; gracias a ellos, que han sido rescatados algunos de la basura, se reconoce la época, los gustos, las modas y los status sociales. Ahora esto se hacen de forma automática por los mismos dispositivos electrónicos que separan las imágenes por carpetas en fechas y lugares, reconocimientos faciales, donde cada uno que cuente con la tecnología apropiada registra su día a día y lo comparte en una red saturada de comida, mascotas, cumpleaños, besos, viajes, etc., estos 
elementos visuales que se comparten, dejan de ser parte de nuestra vida personal y se convierte en una pública, donde no es necesario recordar, ise fotografía para olvidar!

Siendo una generación sin memoria, donde paradójicamente cada imagen es olvidada al mismo tiempo que se comparte; todos en la red mienten, sus mentiras algunas veces salen a la luz gracias a la curiosa mirada de algunas almas sin quehacer que encuentran los errores o en su caso horrores de las selfies, situaciones que su autor no considero o que por su prisa de compartir descuido los detalles de la imagen, dejando al descubierto, un baño, la ropa interior, otro personaje colado en la foto o el desorden de la habitación, por citar los casos mas comunes. Todos parecen felices, en una especie de sobredosis de la imagen, donde es más una competencia virtual de lo fantástico y satisfactorio que nos sentimos, de los lugares que visitamos y las calles que recorremos.

Sin embargo, al hablar de los inicios de la imagen, debemos abordar por cuestiones técnicas la fotografía arquitectónica. Fue la primera en aparecer, con estas escenas oníricas de un Paris desolado, donde solo los edificios se abren paso en la composición, registros de calles que en un lenguaje conceptual está tan lleno de vida y de movimiento que es imposible de capturar en las tomas de tan larga exposición.

La crisis de salud que se vive hace que las personas se recluyan en sus casas, ciudades en todo el mundo a casi 200 años de la aparición de la fotografía muestran calles desoladas, playas con ausencia de personas, animales silvestres en las grandes ciudades, y humanos que cada vez mas parecen ser de otro planeta, donde por sus trajes y mascaras, solo se reconoce y asocia la forma humana, sin embargo, son entes que deambulan combatiendo en las calles un virus que no es posible ver.

Las ciudades a diferencia de antaño, donde la exposición tan larga evitaba el registro de la vida humana, ahora a color y con el registro de fotógrafos aficionados que mas que fotógrafos son ciudadanos contemplando el nuevo orden social, nos muestran imágenes conmovedoras de calles desoladas, imágenes casi al grado apocalíptico de ver a el Santo Pontífice de la fe católica oficiando misa solo en medio de la Plaza de San Pedro. Imágenes que cambiaran la forma en que vemos y reconocemos al orden mundial.

No obstante, antes de la pandemia del Covid - 19, fotógrafos como Olivo Barbieri exploraba plásticamente con su técnica de enfoque selectivo, crea ilusiones no solo de ciudades desoladas, sino de estar pintadas en miniatura como pequeñas maquetas que son a su vez paradójicamente monumentales, este fotógrafo nos regala en cada imagen una ilusión óptica y lúdica, juega con los lugares icónicos de la tierra y recrea en ellos esta sensación no de soledad, sino de juego, de la representación y recreación de fragmentos de espacios colosales, envueltos en un velo de maqueta, la obra de Olivo Barbieri, es una transgresión a la creación humana, al reducir a un nivel de juguete el coliseo, creando esta ambigüedad de lo conocido y lo representado, donde se enfrenta en la dicotomía de lo real - no real, convirtiendo a los entornos urbanos en tema de reflexión desde el punto de vista de lo ambiguo.

El fotógrafo de calle que igual retrata el perro callejero, o un tendedero, se convierte en el ojo voyerista que con la complicidad con el espectador creamos esta mega memoria colectiva. ¿Que sería Instagram sin los fotógrafos de calle?, y en un sentido las ciudades siguen cubiertas de soledad, llenas de personas anónimas unidas en una colectividad que crea un espacio virtual, el cual alimentamos segundo a segundo de todos partes del mundo. El Paris de romance y ensueño que muestran con filtros y sin ellos sigue siendo un ejemplo de cómo el modelo de ciudad se repite en el imaginario colectivo.

\section{Del imaginario a lo simbólico}

La necesidad del recuerdo, de la trascendencia; el ser humano con toda su vulnerabilidad se convirtió en eterno con el recuerdo inequívoco que proporcionó la fotografía, este ser ya no era sujeto a la interpretación de un pintor de la talla que el bolsillo pudiera pagar, si es que esto fuera posible, ahora con el invento de la fotografía quedaría plasmado nuestra imagen para la posteridad, una fotografía, en la vida o quizá en la muerte.

La práctica de fotografiar cadáveres, en especial niños, La Muerte niña o "Angelitos" surge de esta necesidad del recuerdo, de la celebración de la vida que fue interrumpida antes de ser corrompida, escenas post morten de infantes representados como ángeles, santos o en alguna escena como si estuvieran aun con vida, buscar en la muerte la celebración de la inocencia y encontrar en la imagen el medio visual a la trascendencia, de lo tangible de la imagen y lo efímero de la vida. La práctica en desuso a finales del siglo $\mathrm{XX}$, abrió la puerta al cambio del imaginario de la vida eterna, al simbolismo de la naturaleza muerta, retomar una vez más el Vánitas, cadáveres que son estéticamente colocados haciendo una composición impecable retomando alguna escena Renacentista o evocación religiosa, es la fotografía de Joel Peter Witkin donde los elementos utilizados a esta plasticidad visual son similares, sin embargo, la intencionalidad y el contexto cambian en un sentido radical. Witkin busca el transgredir con su obra parte de la condición humana que pocos se atreven a tocar en un medio visual fotográfico. La dualidad, lo efímero de la vida 
y la certeza de la muerte. En ambos casos, cadáveres que son montados en una representación. Donde el resultado es la cuidadosa interpretación de la visión del fotógrafo, su visualización previa de la imagen hasta llegar al resultado deseado. Hablamos de este momento íntimo entre el proceso creativo, la intencionalidad y el contexto en el cual un autor se enfrenta en su deseo de llegar a lo eterno, sin importar la época, o la región donde se elabore la imagen.

\section{Conclusión}

El poder de la imagen

A casi 200 años y menos de 50, cuando la imagen se convierte en digital, las herramientas para capturar el tiempo se diversifican y además el desarrollo exponencial de la tecnología, hace que seamos actualmente una generación adicta a la imagen.

Millones de imágenes se comparten todos los días por redes sociales, viajan entre continentes y se hacen virales, haciendo que todos seamos víctimas cautivas de su poder y de sus mentiras hechas imagen.

Poco ha cambiado desde Niepce, solo la técnica y el acceso a la misma, la imagen desde su aparición hasta nuestros días tiene un poder que casi podemos asumir como mágico, del cual hoy en día no podemos concebir nuestra vida sin el uso y en algunos casos del abuso de la imagen, incluso antes de nacer, los ultrasonidos en 3D, las radiografías, resonancias magnéticas, tomografías, sondas que han sido mandadas fuera de este mundo y dentro de nuestros cuerpos para facilitar la ciencia médica y la carrera espacial por igual, todas imágenes que nos muestran una realidad que en suma son abstracciones del cambiante mundo y su tecnología, además de mostrarnos lo imprescindible que es una imagen que tiene el poder de conectar a personas, alejar a otras, ver enemigos ocultos como los virus y demás paracitos que a simple ojo no es posible ver y mucho menos reconocer.

Cambio significativo es la lectura de estas historias, que a pesar de seguir siendo el momento íntimo donde el fotógrafo responde a las preguntas ¿qué va a fotografiar? ¿Cómo lo va a hacer? y el ¿para que?, la inmediatez con las que se crean, recrean y comparten las imágenes, hacen que cada disparo sea una fotografía mas, y no una menos, evolución de la era análoga donde se pasaba por un proceso de espera y meditación, expectativa y realidad en el proceso mismo de la toma y el trabajo fotoquímico para obtener tan codiciada imagen. Hoy los fotógrafos que retoman la cámara analógica y arman su discurso a través de la recreación del pasado, le dan un significado a la acción de la contemplación, mas allá de la composición, luz, y aspectos técnicos, se genera un estado de conciencia del proceso mismo y de la inevitable espera que conlleva.
Resultado en aplicaciones e hibridaciones con la mezcla de lo analógico a lo digital o en algunos casos a la inversa, creando negativos en digital, sometiéndolos a procesos químicos. Hoy en día el discurso y contexto son los que dan la salida a la técnica y a sus posibilidades creativas. Sin embargo esta tecnología que se desarrolla de forma exponencial no necesariamente nos detiene a recordar, pareciera lo contrario, que fotografiáramos para olvidar, para convertirnos en el inicio de una generación sin memoria ya que las aplicaciones lo hacen por nosotros. Crean recuerdos, fabrican escenarios y hasta construyen vidas a través de la imagen. Vivimos mundos de representación, montajes que creemos que son una verdad absoluta, ya que la estamos viendo a través de un dispositivo, y por el cual compartimos para convencer a los demás de nuestras mentiras. Sin embargo, no importando el fin que tenga el fotógrafo, si es que este es un despistado aficionado con un dispositivo móvil en la mano, o un experimentado artista del lente; ni el medio, sea analógico o digital, o en la hibridación de ambos, la fotografía y el poder de la imagen es una parte de nuestra manera de ver el mundo, de representarlo y de vivirlo, construyendo cuidadosamente nuestras mentiras. $Y$ dejándonos convencer de las mentiras de los demás, creando así experiencias sensoriales, cognitivas que hacen que vivamos nuestras mentiras hechas foto.

\section{Referencias}

[1] Barthes, R. (2011). Camara Lúcida: notas sobre fotografía. Barcelona: Paidós.

[2] Benjamin, W. (1982). La obra de arte en la época de su reproducción técnica. Londres: Penguin.

[3] Capa, R. (2009). Ligeramente desenfocado. Madrid: La Fábrica.

[4]Sontag, S. (1979). On Photograpy. Londres: Penguin Books. (Versión castellana: Sobre la Fotografía, de Bolsillo Barcelona 2008)

[5] McCulling, D. (2002). Unreasonable Behaviour: Autobiography, Vintage, Londres.

[6] McCulling. (2012). [Documentary film] Directed by D. Morris and J Morris. Londres: James Gay Rees. 